\title{
Aspectos de la teoría de la comunicación y su aplicación a la enseñanza de lenguas
}

\author{
José Belmonte Castellano \\ Universidad de Milán
}

Resumen: En este estudio se repasan algunos aspectos fundamentales de la teoría de la comunicación, los códigos de la comunicación no verbal (cinésicos, próxemicos, paralingüísticos, etc.), las diferencias culturales que influyen en el comportamiento del hablante extranjero de una lengua y persisten en su interlengua e intercultura), los errores en la comunicación de tipo pragmalingüístico y sociopragmático. Por último, se presentan las subcompetencias de la compencia comunicativa por su importancia para el logro de una comunicación con éxito o, dicho de otro modo, dotada de adecuación sociolingüística.

Palabras clave: teoría de la comunicación, comunicación no verbal, diferencias culturales, errores, competencias.

Abstract: In this study some fundamental aspects of communication theory are revised: the codes of nonverbal communication (kinesics, proxemics, paralinguistics, etc.); the cultural differences that influence the behaviour of the foreign speaker of a language and persist in their interlanguage and interculture; and the errors in communication of a pragmalinguistic and sociopragmatic type. Lastly, the subcompetences of the communicative competence are presented according to their importance in achieving successful communication or, to put it in other words, according to sociolinguistic fitness.

Key words: communication theory, nonverbal communication, cultural differences, errors, competences. 
1. INTRODUCCIÓN.

La teoría de la comunicación surge a partir de los trabajos realizados por el ingeniero de teléfonos norteamericano Shannon a principios de los años 50 del siglo xx. La investigación en el campo de los mass media y la cibernética da como resultado la aparición de esta ciencia -Teoría de la comunicación- que aborda diversos procedimientos comunicativos, entre los cuales se cuenta la comunicación por medio del lenguaje natural. Desde esta perspectiva se define la comunicación como transferencia de información de un punto a otro.

En este estudio nos planteamos relacionar algunos aspectos de la teoría de la comunicación con la enseñanza del español como lengua extranjera (ELE), haciendo hincapié en la comunicación no verbal, en los errores (pragmalingüísticos y sociopragmáticos) y en la influencia de la interlengua y la intercultura de los alumnos de ELE.

\section{Elementos fundamentales de LA TeORÍA de LA COMUNICACIÓN.}

El modelo clásico de comunicación verbal, propuesto por R. Jakobson se compone de: el emisor (el hablante o el escritor) envía un mensaje al receptor (el lector o el oyente) expresado en un código común (la lengua, el dialecto, el registro, etc.) ubicado en un contexto extralingüístico (referente) a través de un canal físico (el aire en la lengua oral, el folio en la lengua escrita, etc.).

La comunicación se puede estudiar como un proceso o -en la escuela semiótica- como la negociación del sentido. La eficacia del proceso depende del dominio de los códigos, es decir, de la codificación y la descodificación.

Hemos de explicar también el ruido como elemento en el proceso de comunicación. Cualquier perturbación se denomina ruido en la Teoría de la Comunicación. Este término no se refiere aquí sólo a una molestia sonora. Hay dos tipos de ruido:

- De canal: cualquier perturbación en el conducto del mensaje (aquí se incluyen incluso las distracciones entre el emisor y el receptor).

- Semántico: cualquier descodificación, o sea interpretación, equivocada del mensaje.

Para evitar o paliar la inevitable presencia del ruido se recurre a un conjunto de unidades de defensa en la codificación del mensaje: los elementos redundantes. Dicho de otra manera, la redundancia es la parte del mensaje que 
podría omitirse sin que se produzca pérdida de información, por ejemplo, la repetición de los morfemas de género femenino y número plural en: las casas bonitas. Igualmente, pueden cumplir la misma función la elevación de la voz, el subrayado en un texto escrito, etc.

A partir de la Teoría de la Comunicación, Shannon y Weaver (1963) presentan el conocido esquema de la comunicación (emisor, mensaje, receptor, código, etc.) en el que distinguimos dos fases:

1) Proceso de codificación, denominado onomasiológico.

Selección de signos (formas sonoras, gráficas, etc.) para transmitir una realidad.

2) Proceso de descodificación, denominado semasiológico.

Consiste en la interpretación de los signos para descifrar o comprender la realidad transmitida.

Algunos lingüistas consideran que la comunicación verbal es, en realidad, mucho más compleja y señalan en el modelo de Shannon y Weaver dos puntos débiles:

1) La fuerza ilocutiva no se recoge en este modelo 'emisor - mensaje - receptor'.

El mensaje "Te llamaré" puede ser una promesa, una simple afirmación o una amenaza. Un enunciado como “¿Qué planes tienes para el fin de semana?" puede interpretase como una invitación implícita o no, según la situación comunicativa.

2) Este modelo no tiene en cuenta los elementos de la situación comunicativa.

Los lingüistas insisten en que el discurso es algo más que un mensaje enviado por un emisor a un receptor. Además, este modelo no cuenta con el hecho de que el emisor utiliza, al enviar un mensaje, el principio de cooperación, además de las estrategias de cortesía.

\section{COMUNICACIÓN NO VERBAL Y DIFERENCIAS CULTURALES.}

En la enseñanza de elE es muy importante otorgar la suficiente importancia a la comunicación no verbal, ya que para comunicarnos usamos también códigos no verbales como los gestos, las muecas, posturas, las distancias, etc. 
Es cierto que tradicionalmente en la enseñanza de lenguas se le otorga más importancia a la lengua escrita en detrimento de la lengua oral y esto se debe a numerosos factores y a las mayores dificultades metodológicas para la enseñanza de la lengua oral (Cassany et al. 1994; Georgíeva Níkleva 2008). Por eso, es importante que el docente planifique su enseñanza y aprendizaje, tan necesario para la competencia comunicativa del alumno de ELE.

La comunicación no verbal incluye todos los códigos no lingüísticos que normalmente acompañan a la comunicación verbal. Es importante saber y enseñar las diferencias culturales que existen entre las distintas lenguas y culturas (Cesteros 1999, Níkleva 2011). A continuación recordamos algunos de los códigos no verbales:

- Código cinésico: movimientos corporales, gestos, etc.

- Código proxémico: la distancia entre los interlocutores en una conversación.

- Código paralingüístico: los elementos relacionados con la voz (tono, timbre, intensidad, ritmo, entonación, etc.)

- Códigos icónicos: las señales de tráfico, las estrellas de los hoteles, etc.

- Código cronémico: todo lo relacionado con el tiempo y sus unidades.

- Otros: el lenguaje de signos, el código morse, el braille, etc.

En el proceso de enseñanza/aprendizaje de elE hay que tener en cuenta que los códigos semióticos se caracterizan por numerosas diferencias culturales que deberíamos introducir en el aula, otorgándoles la importancia que se merecen para conseguir una mejor competencia comunicativa y para disminuir los efectos del choque cultural en una situación de inmersión lingüística.

Según Níkleva (2009: 34), el alumno de una lengua extranjera, en situación de inmersión, ticos, pero pasada la etapa de euforia turística, se da cuenta asombrado de que corre el riesgo de ahogarse en el mar de diferencias en las pautas culturales. La gente a su alrededor no se comporta normal... ¿o es él el que no lo hace? 
Esto se debe al choque cultural que todo hablante de una lengua extranjera experimenta en situación de inmersión. De ahí, la importancia de diseñar una enseñanza integrada de lengua y cultura (Manga 2008).

¿En qué puede consistir el choque cultural al que hemos aludido anteriormente? Puede referirse a nociones de amistad, jerarquía, pareja sentimental, hospitalidad, etc. Puede referirse también a aspectos tan cotidianos como el saludo y los horarios. Estas son algunas de las razones que provocan el choque cultural (Oliveras 2000, Níkleva 2011), definido en el Diccionario del Centro Virtual Cervantes (Instituto Cervantes 1997-2013) de la siguiente manera:

Este término, conocido también con el vocablo inglés cultural shock, se refiere al conjunto de reacciones que puede llegar a experimentar un individuo, y por extensión el aprendiente de segundas lenguas o lenguas extranjeras, al entrar en contacto por primera vez con una cultura diferente de la propia, cuyo grado de conocimiento puede ser muy diverso entre individuos. Tal impacto suele tener una variable afectiva y una variable cognitiva. Desde el punto de vista afectivo, es posible que el sujeto experimente emociones como el miedo, la desconfianza, la incomodidad, la ansiedad o la inseguridad. Desde el cognitivo, puede experimentar un conflicto cognitivo entre su conocimiento del mundo por un lado y los marcos de conocimiento, los valores o las interpretaciones propias de la nueva cultura, por otro.

Por consiguiente, volvemos a resaltar la importancia de incluir en la enseñanza/aprendizaje de una lengua extranjera las diferencias culturales como parte de las competencias sociolingüística, sociocultural e intercultural.

Para que el choque cultural no provoque rechazo y para lograr el acercamiento a la cultura meta, hay que aprovechar la clase de ELE que en palabras de Verde Peleato (2007: 467), "nos presenta una oportunidad única para transformar la ética de los ciudadanos en una ética de convivencia interpersonal para que el encuentro de culturas no sea un "choque" o un "conflicto" sino que se produzca una fusión de horizontes".

\section{ERRORES EN LA COMUNICACIÓN.}

En la enseñanza del español como lengua extranjera conviene distinguir entre faltas y errores. Es importante que el docente sea consciente de que estos provienen tanto de la insuficiente competencia comunicativa como de la lengua y la cultura nativa del alumno de ELE y por eso persisten mucho tiempo en la interlengua y la intercultura del aprendiz de elE. Veamos a continuación las definiciones del Instituto Cervantes (1997-2013) de estos dos términos:

El error pragmático se define de esta manera: 
Se entiende por error pragmático el que es cometido, tanto en la producción como en la recepción, por un desconocimiento de las normas o valores socioculturales (enlace a «pragmática») de la lengua. Quiere esto decir que para dar cuenta de un error pragmático sólo puede hacerse teniendo en cuenta factores extralingüísticos. En ocasiones, el aprendiente produce o comprende un enunciado gramaticalmente correcto y con un sentido literal idéntico en ambas lenguas, pero con una fuerza ilocutiva o con un valor comunicativo distinto en una y otra cultura; por ejemplo cuando un hablante hispanohablante le pregunta a su interlocutor no nativo[¿Vendrás a la fiesta?] con la intención de invitarlo, puede ocurrir que el no nativo se quede en el significado literal [pedir información] y no interprete la fuerza ilocutiva del enunciado [invitación], con el consiguiente malentendido.

Conviene saber que existen diferencias entre el error pragmalingüístico (Thomas 1983) y el sociopragmático (Escandell 1996) (citado por Instituto Cervantes, 1997-2013).

Un error pragmalingüístico tiene lugar cuando se usa en una lengua una fórmula propia de otra, con un significado del que carece en la primera. Así, cuando un estudiante formula el enunciado [No es posible entrar] en lugar de [No se puede entrar], indicando prohibición en lugar de imposibilidad física. Este tipo de error pragmático afecta a los aspectos más convencionalizados y más ritualizados de las relaciones interpersonales, por ejemplo, los saludos, las despedidas, las felicitaciones. Por tanto, el conocimiento y uso adecuado de las fórmulas propias de cada comunidad constituye pues uno de los objetivos centrales del aprendizaje de una lengua.

Un error sociopragmático consiste en el traslado a otra lengua de las percepciones sociales y las expectativas de comportamiento propias de otra cultura. Así, por ejemplo, ante un elogio o cumplido [Qué bonita la chaqueta que llevas hoy], en la cultura hispana, el destinatario del cumplido tiende a mitigar el valor de éste con exponentes del tipo [Es barata/ hace muchos años que la tengo/ era de mi padre, está muy vieja]. En cambio, en la cultura anglosajona, se agradecerá el cumplido sin más [Gracias/sí, lo sé], lo que, desde una cultura hispana, resultaría descortés. Lo que cambia en estos casos es la interpretación del enunciado y, sobre todo, la valoración social que éste recibe.

Hay que programar la superación de los errores y las faltas y ser conscientes de los que provienen de la lengua y la cultura nativas del alumno de ELE.

\section{LA COMUNICACIÓN Y LA COMPETENCIA COMUNICATIVA.}

\section{Una definición actual del concepto lo explica así:}

La competencia comunicativa es la capacidad de una persona para comportarse de manera eficaz y adecuada en una determinada comunidad de habla; 
ello implica respetar un conjunto de reglas que incluye tanto las de la gramática y los otros niveles de la descripción lingüística (léxico, fonética, semántica) como las reglas de uso de la lengua, relacionadas con el contexto sociohistórico y cultural en el que tiene lugar la comunicación (Instituto Cervantes, 1997-2013).

Desde que Hymes introdujo el concepto de competencia comunicativa en los años 70 del siglo $\mathrm{xx}$, este concepto ha tenido un largo recorrido lleno de modificaciones, ampliaciones, etc. Ya con él la competencia gramatical quedó integrada en una competencia más amplia. Posteriormente, M. Canale (1983) describe la competencia comunicativa como un conjunto de cuatro competencias interrelacionadas:

- competencia lingüística

- competencia sociolingüística

- competencia discursiva

- competencia estratégica

Más tarde J. Van Ek (1986) añade la competencia sociocultural y la competencia social.

El Marco común europeo de referencia para las lenguas recoge las siguientes competencias comunicativas de la lengua: lingüísticas, sociolingüísticas y pragmáticas.

El modelo de L. Bachman (1990) concibe la competencia estratégica como una capacidad de comportarse y además, la competencia lingüística coincide con la comunicativa en los modelos anteriores y es la que es capaz de producir interacción y comunicación.

\section{ConCLusiones.}

El docente de elE tiene que programar la superación de los errores en la interlengua e intercultura de los alumnos, teniendo en cuenta la competencia comunicativa que es el último objetivo en el proceso de enseñanza/aprendizaje de ELE.

Es necesario atender aspectos tanto de la comunicación verbal como de la no verbal, centrándose en las diferencias culturales que se presentan entre la lengua y cultura de origen, por una parte, y la lengua y cultura meta, por otra. 
BiBLIOGRAFÍA

BaCHman, L. (1990) Habilidad comunicativa. Competencia comunicativa. Documentos básicos en la enseñanza de lenguas extranjeras, Madrid: Edelsa, pp. 105-129.

Canale, M. (1983) De la competencia comunicativa a la pedagogía comunicativa del lenguaje. Competencia comunicativa. Documentos básicos en la enseñanza de lenguas extranjeras, Madrid: Edelsa, pp. 63-83.

Cassany, D., Luna, M., Sanz, G. (1994) Enseñar Lengua. Barcelona: Graó.

CESTEROS, A. M. (1999). Comunicación no verbal y enseñanza de lenguas extranjeras. Madrid: Arcos/Libros.

Consejo de Europa (2002) Marco Común Europeo de Referencia para las Lenguas. Ministerio de Educación, Cultura y Deporte. Recuperado el 11 de enero de 2013 de: http://cvc.cervantes.es/ensenanza/biblioteca_ele/marco/cvc_mer.pdf.

Escandell, M. a V. (1999) Los fenómenos de interferencia pragmática. Didáctica del español como lengua extranjera. Madrid: Colección Expolingua, cuadernos de tiempo libre. 1996, pp. 95-110.

GeorgíeVA NíkLeva, D. (2008) La oposición oral/escrito: consideraciones terminológicas, históricas y pedagógicas. Didáctica. Lengua y Literatura, 20, pp. 211227.

Instituto Cervantes (2007). Plan Curricular del Instituto Cervantes. Madrid: Biblioteca Nueva.

Instituto Cervantes (1997-2013) crc (Centro Virtual Cervantes). Diccionario de términos clave de ELE. Recuperado el 12 de enero de 2013 de: http://cvc.cervantes.es/ ensenanza/biblioteca_ele/diccio_ele/diccionario/compintercult.htm.

Llobera, M. (ed.) (1995) Competencia comunicativa. Documentos básicos en la enseñanza de lenguas extranjeras. Madrid: Edelsa.

ManGA, A.-M. (2008) Aprendiendo a hablar el español lengua-cultura extranjera. Ogigia, 4, pp. 37-46.

NíkLeVA, D. G. (2009) La convivencia intercultural y su aplicación a la enseñanza de lenguas extranjeras. Ogigia - Revista Electrónica de Estudios Hispánicos, 5, pp. 29-40.

NíkLEva, D. G. 2011. Aspectos interculturales y pedagógicos del choque cultural para inmigrantes de origen búlgaro en Andalucía. MarCoELE, 13, pp. 1-11.

Oliveras VilaseCA, A. (2000) Hacia la competencia intercultural en el aprendizaje de una lengua extranjera. Estudio del choque cultural y los malentendidos. Madrid: 
Edinumen, Memorias para el aprendizaje, Serie Máster E/LE Universidad de Barcelona. Madrid: Edinumen.

Oliveras VILASECA, A. (2005) La competencia intercultural en el aprendizaje de una lengua extranjera: el análisis de malentendidos culturales en el aula de ELE. Mosaico n. ${ }^{\circ} 16$, p. 24-26.

Rodríguez MuÑoz, F, Ridao Rodrigo, S. (2012) La oralidad en Educación Secundaria: Legislación y libros de texto de lengua y literatura españolas. Didáctica. Lengua y Literatura, 24, pp. 341-358.

Thomas, J. (1983) Cross-Cultural Pragmatic Failure. Applied Linguisstics, 4, pp. 91112.

VAN EK, J. (1986). Objectives for Foreign Language Learning (vol. I). Estrasburgo: Council of Europe.

Verde Peleato, I. (2007)_Claves para lograr una comunicación intercultural adecuada en el aula de E/LE. En Martí Contreras, Didáctica de la enseñanza para extranjeros: Actas del I Congreso Internacional de Lengua, Literatura y Cultura Española. Valencia.

WeAVER \& SHANNON (1963) The mathematical theory of communication. Illinois: University of Illinois Press. 
